\title{
Rir do poder e o poder do riso nas narrativas e performances kaxinawa
}

\author{
Els Lagrou \\ Professora do Departamento de Antropologia - IFCS/UFRJ
}

RESUMO: O humor grotesco das pantomimas e dos mitos, o humor festivo das brincadeiras e o humor crítico dos excessos em mitos e sketches podem ser lidos como formas de conhecimento nativo sobre o mundo e sobre as relações que mantêm esse mundo interconectado. A exegese nativa da imagética humorística revela valores cruciais relacionados às concepçōes kaxinawa sobre socialidade e agência ritual. Estamos lidando com discursos icônicos sobre a qualidade das relaçôes entre pessoas e entre pessoas e o mundo animado. O humor do corpo grotesco, que faz dialogarem partes de corpos como forças autônomas, e o humor festivo, cujo riso contamina a moral dos "donos" das substâncias, têm alta eficácia ritual, motivando forças cósmicas a agirem em prol da humanidade. Qual é o saber expresso pelo humor? O humor expressa um conhecimento de como agir sobre o mundo que os protagonistas dos mitos careciam. Nos mitos, os poderosos donos de saberes cruciais à vida eram conquistados e mortos. No ritual, estes mesmos seres são "alegrados" e seduzidos. A agência ritual subverte o tempo mítico do conflito para produzir o tempo histórico, um tempo no qual pessoas são produzidas com base nas qualidades construtivas de seres poderosos, conhecidos por suas capacidades predatórias.

PALAVRAS-CHAVE: etnologia, Kaxinawa, humor festivo, humor grotesco, ritual, mito. 


\section{Introdução}

Dedico minha contribuição para este número em homenagem à obra de Joanna Overing a um curioso fenômeno, pleno de conseqüências epistemológicas, que tem detido sua atenção nos últimos anos: ao ler monografias sobre cosmologias ameríndias, ressalta a forma ambígua pela qual os ameríndios apresentam seus deuses. Parece até haver uma tendência destes se tornarem tanto mais grotescos quanto maior é o poder que os indígenas lhes atribuem. A história analisada por Overing (1986) de Kuemoi, deus criador mais poderoso dos Piaroa que se transforma em criatura grotesca e cuja trágica história conta o fim dos deuses na terra, mostra de forma clara o argumento que tentarei desenvolver neste trabalho: a atitude que acompanha a esfera do sagrado entre os ameríndios não exclui o humor, muito pelo contrário, o grotesco faz parte da imagem do divino tanto quanto do humano. O poder provoca o riso assim como o próprio riso tem poder. Os aspectos risórios marcam o tempo de criação, tempo de bruscas mudanças, conquistas e destruiçôes, que é contrastado com o tempo atual em que vivem os Piaroa, no qual o aspecto não cumulativo é uma conquista da vida em comunidade, em que se evitam os perigos dos excessos divinos. A arte do viver piaroa está na dosagem certa do conhecimento produtivo, pois se sabe que excesso de conhecimento pode envenenar a vida dos sentidos (Overing, 1992).

Existem inúmeros exemplos desses deuses imperfeitos dos ameríndios, seres cujos atos atingem também sua aparência física, transfigurando-os, caricaturizando-os, e minha intenção é mostrar neste artigo que a utilização do humor para falar da imperfeição dos deuses tem algo de muito importante a nos dizer sobre a teoria nativa do conhecimento. ${ }^{1}$ Para os ameríndios, todo pensamento produz efeitos sobre o mundo e, por essa razão, ética, estética e cognição estão intimamente relacionadas. 
Meu objetivo é refletir sobre a ligação entre esse tipo de humor grotesco e a imaginação moral e cosmológica no caso específico dos Kaxinawa. ${ }^{2}$ Procuro ilustrar como as atitudes perante o humor e os diferentes tipos de humor privilegiados variam de acordo com o sistema de valores e as questóes epistemológicas privilegiadas por uma cultura. Começo com uma pequena incursão pelo tratamento do riso no pensamento ocidental que influenciará a abordagem do tema pela antropologia.

\section{Uma reflexão sobre o riso}

Ao começar uma reflexão sobre o lugar do riso na tradição filosófica ocidental, constata-se um paradoxo: o pensamento acadêmico dá prova de uma histórica falta de senso de humor e demonstra uma dificuldade de pensar o riso e o risível como temas relevantes em análises "sérias" de sistemas sociais, políticos ou cosmológicos. Seria a antropologia, além de constitutivamente uma antiarte (Gell, 1992), também essencialmente anti-humorística? $\mathrm{O}$ riso e a arte aparecem nesse paradoxo como tópicos relacionados, tanto no que se refere ao fascínio que exerceram sobre o pensamento e a filosofia modernos quanto no que se refere à dificuldade de escrever algo antropologicamente "novo" ou "certo" sobre eles.

Bateson (1972) propõe uma aproximação do jogo e da arte, alegando que ambos trabalhariam com um código comunicativo comum, o código icônico, diferente do código gramatical das línguas faladas. No código icônico (também atuante nos sonhos e nas mímicas), aquilo que será negado é primeiro encenado, e a negação, a temporalidade e o caráter hipotético da afirmação não são passíveis de serem mencionados. As possibilidades de relação são apenas apresentadas, presentificadas, e o caráter temporal e modal do tema apresentado precisa ser inferido pelos envolvidos por meio do desenrolar da cena. Esse código tem como 
LAGRou, E. RiR Do PODER E O PODER DO RISO NAS NARRATIVAS...

objeto de comunicação as próprias relações entre o sujeito e as outras pessoas, assim como entre o sujeito e o ambiente. Mais importante que a informação recebida é a confirmação de que a visão sobre nossa relação com os outros e com o mundo está correta.

Essa abordagem aproxima arte, humor e jogo em uma dialética experimental que brinca com a mimese e a alteridade, sendo a mimese, segundo Taussig (1993), uma maneira de nos tornarmos temporariamente outros. Esse tema é especialmente relevante para os Kaxinawa, que partilham com seus parentes pano uma particular obsessão pela mimese enquanto brincadeira, para experimentar com o ponto de vista do outro: isso se vê nas brincadeiras de inversão dos papéis de gênero, assim como nas brincadeiras de imitar o comportamento de branco. O humor carnavalesco de muitos dos seus ritos gira em torno do tema do se tornar outro de forma jocosa e temporária.

Alberti ressalta a mesma relação. Cita Warning, que "aproxima o riso e o risível do mundo da ficção e do poético, como formas de expor outras possibilidades, para além dos sistemas de sentido fechados" (Alberti, 2002, p. 31), e Huizinga (1980), autor de Homo Ludens, que já em 1938 destacava essa relação no caso específico do jogo, em que tanto o jogo quanto a arte seriam baseados na manipulação de certa imaginação da realidade e de sua transformação em imagens.

Gadamer se pergunta: "What is the anthropological basis of our experience of art? I should like to develop this question with the help of the concepts of play, symbol, and festival' (1995, p. 22). O jogo e o festival não permitem a clássica distância entre quem olha e quem brinca, o jogo é um brincar com possibilidades sem fim declarado, "a form of nonpurposive activity" (id., p. 23). Essas atitudes mentais aproximam a extrema seriedade do jogo infantil da igualmente extrema seriedade do jogo na arte moderna. Para entender essa arte, é preciso compreender as razões profundas de "The play of Art": 
Revista de Antropologia, São Paulo, USP, 2006, v. 49 no 1.

Play and seriousness, the exuberance and superabundance of life, on the one hand, and the tense power of vital energy on the other, are profoundly interwoven. They interact with one another, and those who have looked deeply into human nature have recognized that our capacity for play is an expression of the highest seriousness. For we read in Nietzsche (1966, p. 83), "Mature manhood: that means to have found again the seriousness one had as a childin play". Nietzsche also knew the reverse of this as well, and celebrated the creative power of life - and of art - in the divine ease of play.

Contra os que alegam que o riso não foi suficientemente estudado, Alberti mostra "a tendência atual para se conferir ao riso um lugar privilegiado na compreensão do mundo" (2002, p. 7), especialmente na filosofia. Mostra como, desde Nietzsche e de forma manifesta na filosofia de Bataille, o riso viria a ocupar o imperativo de ir além do compreensível, dos limites estabelecidos pela razão - o riso crítico e irônico ri das sucessivas mortes de Deus, do Homem, da Arte, das Verdades. Trata-se de um riso provocador, libertador e divino como queria Nietzsche, para se tornar depois um riso cada vez mais melancólico: um riso humanista e niilista, um riso banal e sutil. Mas Alberti alerta, com uma epígrafe de Ritter (1940), que "Foi dito que refletir sobre o riso faz ficar melancólico" (id., p. 25).

Os filósofos mostram a ligação não só entre riso e alegria, autonomia e soberania, mas também entre riso e controle social, exclusão e agressividade, entre o riso e a dor, o riso e a morte. O riso seria, segundo Aristóteles, o que melhor caracterizaria a condição humana. Quem já observou o desafio intelectual e emocional que é para uma criança entre 2 e 3 anos tentar entender os vários registros possíveis do riso, como a diferença crucial entre "rir de" e "rir com", além das sutis gradações existentes entre estes dois pólos, não duvidará da sua complexidade. Terá também a oportunidade de observar a prioridade, sugerida por Bateson, 
LAGRou, E. RiR Do PODER E O PODER DO RISO NAS NARRATIVAS...

da "confirmação obtida com relação à qualidade da relação" quanto ao "conteúdo informativo da comunicação". Chega-se assim à conclusão de que existem tantos tipos de risos, sorrisos e gargalhadas quanto existem situações psicossociais diversas.

Em um de seus artigos sobre a eficácia do riso entre os Piaroa, Overing (2000) chama a atenção para uma verdadeira epistemologia do ridículo entre os ameríndios, mostrando como é epistemologicamente crucial perguntar por que os mitos piaroa enfatizam o risível, o erótico e o obsceno e por que dão tanta importância ao lado hilário e escatológico do comportamento divino. As maiores obscenidades encontram-se nos cantos mais sagrados do xamã piaroa, pois essas palavras desmedidas são palavras de poder, e seu uso é cuidadosamente orquestrado. Existe uma filosofia política por trás dessa estética do grotesco; um discurso que encontra seu principal significado numa política moral da procura de relaçôes intersubjetivas que sejam tranqüilas e produtivas. A ambigüidade e absurdidade da origem da condição humana incorporam forças latentes de disrupção escondidas atrás dos constantes mas frágeis esforços dos seres humanos de criar uma vida social, e essa é a razão por que um senso de humor permanente é tão central para a filosofia social igualitária dos Piaroa. Procura-se aqui, na prática das narrativas e das performances indígenas, como na reflexão sobre o riso na filosofia moderna, aprender algo sobre a relação específica que liga certo humor a certa filosofia de vida.

Por mais que se tenha pensado filosoficamente sobre a função do riso para o pensamento ocidental moderno, continua valendo a crítica de Overing de que o fenômeno foi muito precariamente pesquisado pela etnologia. ${ }^{3}$ Claro, temos os clássicos estudos de Mauss (1969), de Radcliff-Brown (1952) e dos africanistas sobre as relaçóes jocosas, os famosos joking relationships, sua função social de alívio por meio da inversão controlada e sua relação com a estrutura social. Somente certas 
Revista de Antropologia, São Paulo, USP, 2006, v. 49 no 1.

pessoas podem brincar em determinados contextos. Carneiro da Cunha (1978) retoma esse tema clássico na análise da relação entre a amizade formal e a construção da pessoa entre os Krahó, na qual salienta a importância da alteridade e da distância produzida pela relação prazenteira. Evitar uma pessoa e dela manter distância teriam o mesmo efeito estrutural que caçoar impunemente de uma pessoa que não pode revidar, o efeito de marcar a alteridade e ajudar na definição da identidade.

Ou seja, pensou-se de fato sobre o uso e controle social das brincadeiras, mas não muito sobre a pergunta "de que riem os índios?”. Clastres se colocou essa questão e chegou à conclusão de que os Chulupi "têm a paixão secreta de rir daquilo que temem" (2003, p. 163), seus xamãs e as onças - seres respeitáveis dos quais não se ri no cotidiano, ou seja, rise do próprio medo e do próprio conceito de poder. Surrallés sugere que "Lo que hace reír del humor no es a menudo otra cosa que constatar la posibilidad que tiene solo el humor para decir lo que seria indecible de otra manera" (2003, p. 100).

É de Lévi-Strauss (1991, p. 110-32), nas Mitológicas, a primeira reflexão sistemática sobre o tema entre os ameríndios. $\mathrm{O}$ autor mostra como a gargalhada é associada ao excesso de abertura, que pode ser perigoso para a pessoa que ri. A abertura de um dos orifícios do corpo pode corresponder estruturalmente a de outros. Overing (2000, p. 71) mostra como em um mito piaroa essa lógica se aplica a uma doença chamada de loucura, que consiste em rir descontroladamente e que pode se manifestar também por meio de dois outros sintomas: a promiscuidade sexual e a dor de barriga.

Beaudet analisa o aspecto estético e sonoro dos diferentes tipos de riso encontrados entre os Waiápi, em que cada tipo de riso expressa atitudes e sentimentos diferentes. Mulheres riem de modo diferente de homens, mantendo a mão em frente à boca, gesto que evoca a associação estrutural proposta por Lévi-Strauss (Beaudet, 1996, p. 93). O autor 
Lagrou, E. Rir do poder E O PODER Do Riso nas NARRATIVAS...

chama a atenção para o caráter socialmente construído dessa expressão sonora, que, assim como o choro, se aproxima em alguns casos do canto ou se associa a determinadas formas de fala.

Com Overing, entretanto, reencontramos uma preocupação mais epistemológica em ligar o riso a uma maneira de se pensar a si mesmo e de pensar o mundo. Não interessa, portanto, saber somente quem pode rir quando e de que, mas como o riso se relaciona a uma determinada cosmologia e a uma imaginação moral.

Outro campo em que a importância do riso se impõe é nos estudos de performance e das manifestações populares festivas e carnavalescas. Nesse campo a obra de Bakhtin tem sido influente ao iluminar a base cosmológica do grotesco na cultura popular, exatamente o que Overing propõe fazer para as culturas ameríndias.

Steward, ao falar do corpo grotesco nos rituais carnavalescos de Bakhtin, afirma: "The body presents a paradox of contained and container at once. Thus our attention is continually focused upon the boundaries or limits of the body" (1993, p. 104). Os fluidos que cruzam essas fronteiras ganham, dessa forma, muita atenção cultural. A antropologia clássica não se esqueceu dos tabus que controlam o contato com as substâncias que entram e saem do corpo (sêmen, cuspe, urina, sangue) (Leach, 1972; Douglas, 1966; Seeger, Da Matta e Viveiros de Castro, 1979). O humor grotesco lida com a mesma matéria-prima. Assim, Bakhtin (in Steward, 1993, p. 105) caracterizou o corpo grotesco como "um corpo no processo de devir". O corpo grotesco sofre um aumento hiperbólico dos intestinos, órgãos sexuais, boca e ânus.

All these convexities and orifices have a common characteristic: it is within them that the confines between bodies and between the body and the world are overcome: there is an interchange and an interorientation. (ibid.) 
Revista de Antropologia, São Paulo, USP, 2006, v. 49 no 1.

The grotesque body, as a form of the gigantic, is a body of parts. Those productive and reproductive organs which are its focus come to live an independent life of their own. The paradigm of the grotesque is often the isolation and display of the exaggerated part. (ibid.)

Steward contrasta essa exibição grotesca do carnaval medieval com os freak shows dos séculos XVIII e XIX, nos quais o grotesco exibido é um corpo inteiro (de anão ou gêmeos siameses) e serve não para unir e misturar os envolvidos como num carnaval, mas para separar o público na sua normalidade da figura grotesca em exibição.

Muito do que Bakhtin detectou na cosmologia do grotesco carnavalesco se aplica também ao significado do grotesco para os ameríndios. Como salienta Steward, trata-se de uma reflexão sobre os processos produtivos e reprodutivos, aumentados em temas cósmicos, desprendidos de corpos individualizados e indivisíveis. Os corpos em festa participam de um corpo maior e são, eles mesmos, divíduos em vez de indivíduos, são corpos permeáveis, partíveis - enfatiza-se a relação entre corpos e entre o corpo e o mundo.

A fórmula encontrada tanto em Bakhtin quanto em Bateson para falar do jogo e do humor grotesco é a de que estes falam da relação entre pessoas-corpos e entre pessoas-corpos e o mundo. Essa recorrência de dois temas metacomunicativos, a qualidade da relação entre pessoas e da relação entre as pessoas e seu mundo, será o eixo a organizar a apresentação do humor kaxinawa nas narrativas e nas "brincadeiras".

É preciso antes justificar a superposição acima proposta de pessoa e corpo. Os Kaxinawa falam de "corpos pensantes" quando se referem à pessoa viva. O pensamento se encontra incorporado em um corpo pensante, pois, somente quando o corpo está em repouso ou enfraquecido, surgem almas independentes desse corpo. $\mathrm{O}$ conhecimento mora no corpo e se concretiza por meio dele (Kensinger, 1995; McCallum, 2001; 
Lagrou, 1998, 2000). Por essa razão, para a cosmologia kaxinawa, tratase de pensar, por um lado, as relações corpos-pessoas e, por outro, aquelas entre corpo-pessoa e mundo.

Uma primeira questão diz respeito à conceituação e tematização da relação entre semelhança e diferença, e do poder de agir sobre ou incorporar o outro - o outro gênero ou o estrangeiro. A segunda tematiza a relação com outros seres não humanos que habitam os espaços de seu ambiente. Aqui a questão relacional é a mesma: saber como seduzi-los, aumentando seu ânimo e provocando sua vontade de se deixar capturar. A fertilidade humana está ligada à fertilidade dos seres da floresta, das plantas e dos animais. Para aumentar um e outro, é preciso o conhecimento de como agir sobre o ânimo e as forças produtivas desses seres. A encenação ritual desses aspectos envolve tanto o puro humor festivo, em que se canta e dança para alegrar os donos das espécies (cantos chamados benimai, "para alegrar"), quanto o humor grotesco, em que as partes dos corpos e os elementos referentes à produção e reprodução ganham vida própria e amplificada.

\section{Nawa Paketawã e os poderes da sedução}

Quando grandes o suficiente para andar, Nete contou a seus filhos que tinham um tio, Nawa Paketawã, este havia saído muito tempo antes do dilúvio. Paketawã era o irmão de Nete. A esposa de Paketawã tinha morrido jovem e ele, por estar sozinho, chorava, não tinha ninguém para plantar e colher legumes para ele. $\mathrm{O}$ cunhado de Paketawã tinha uma esposa, a prima paralela de Paketawã. Toda vez que esta mulher se sentava, o fazia de um modo que ele pudesse ver sua vagina. Quando tecia cestos, fazia com que visse sua vagina e logo depois ia para sua rede, convidando-o para uma relação sexual. Paketawã deitou na rede, namo- 
Revista de Antropologia, São Paulo, USP, 2006, v. 49 no 1.

rou a prima e pediu para se casar com ela. No meio tempo, o marido chegou em casa e as pessoas contaram-lhe o que havia ocorrido.

Nawa Paketawã e sua amante deixaram a aldeia de Nete e viajaram rio abaixo. $\mathrm{O}$ rio que seguiam desaguou em um rio de águas brancas, que desaguou em um rio de águas vermelhas, que, por sua vez, desembocou em outro de água amarela, até que chegaram em um enorme rio de espuma branca: a raiz do céu. Em cada rio que andavam, suas pernas ficavam marcadas pela cor das águas. E, nos rios que passavam, repetiam um mesmo ritual: Nawa Paketawã preparava o veneno de pesca (puikama) e o jogava no rio; depois se sentava à margem para olhar os pêlos pubianos da mulher enquanto ela despia a saia curta e entrava nua na água para catar os peixes que iam boiando.

Diversas versóes enfatizam a saia curta da mulher. ${ }^{4}$ Esse detalhe parece importante, visto que o costume kaxinawa prescreve o uso de saias que toquem os joelhos. Outro detalhe fundamental na cena descrita acima é o fato de o marido ficar sentado e olhar sua mulher pescar sozinha. Normalmente a pesca com puikama é uma atividade coletiva em que homens, crianças e mulheres pescam juntos. Para clarificar ainda mais o significado dos detalhes descritos no mito relativo ao comportamento do casal, é necessário introduzir dados do comportamento kaxinawa: a extrema discrição com que mulheres sentam e até mesmo pescam, evitando a exposição da genitália por meio de movimentos corporais controlados. Uma versão do mito descreve o efeito da visão sobre o marido, contando que esta o deixa "alegre" e que o fato de ser o único que a vê provoca nele um forte desejo (kemu-aya: "o deixa com saliva”).

Esse não é o único mito que usa o tema da pesca com puikama para evocar a imagem do desejo sexual associado a casos extraconjugais. O mito de Bane, contado duas vezes a mim durante a pesquisa de campo, sempre na véspera de uma expedição coletiva de pesca, associa o relacionamento extraconjugal do herói com a mulher de seu irmão a 
seu sucesso na pesca. Bane fica atrás e não pesca junto com os outros porque está namorando. As pessoas voltam da pesca sem saber onde ele está e insinuam que o casal "voltará de mãos vazias". Depois do namoro, no entanto, Bane pega em pouco tempo mais peixe do que o grupo inteiro e retorna para a aldeia triunfante.

Se expedições de caça requerem precauçóes com relação a odores sexuais, expediçõos de pesca, pelo contrário, associam-se à feminilidade e sexualidade. A relação entre odor e sucesso na caça e na pesca é explicitada pelos Kaxinawa. Eles consideram que o sucesso na expedição devese mais ao poder de atração e sedução (por imitação e simulacro) do que à força. Peixes são atraídos pelo cheiro do sexo, pela secreção feminina, enquanto o mesmo cheiro pode afastar a caça do caçador.

O papel da atração na caça explica o porquê da consulta à jibóia para magia de caça e não à onça (inu keneya), que surge no mito mais como bom trabalhador de roçado e conhecedor de plantas medicinais do que como caçador. Seu irmão, a onça-vermelha, por outro lado, tem fama de bom caçador. Depois de suas expedições bem-sucedidas (e não antes, como acontece com Bane), a onça-vermelha conquista a esposa de seu irmão. Uma das razões por que a onça-pintada é um fracasso na caça é o ciúme. Preocupada com a possibilidade da traição, a onça-pintada ciumenta não consegue ir longe, anda em círculos ao redor da casa, vigiando a esposa. Retorna sem caça e, mais, não consegue impedir a traição suspeitada. Todas essas histórias falam da moral sexual e da administração das emoções, e são consideradas extremamente engraçadas.

Voltemos à figura Nawa Paketawã, aquele que demonstra o desejo sexual de forma tão forte e sem compromisso que se torna uma força destrutiva da sociabilidade, mas, por outro lado, é fonte de conhecimento cultural e poder mágico. Paketawã deseja tudo aquilo que é socialmente proibido, a começar pelo fato de que a mulher que deseja é casada. O desejoso não somente a seduz, mas a afasta de seu marido e de sua 
Revista de Antropologia, São Paulo, USP, 2006, v. 49 no 1.

família, levando-a para viver longe, na terra de estrangeiros. Essa mulher pertence à categoria de não casável, pois é sua prima paralela e é com ela que realiza diariamente atividades que não representam o sexo legítimo, conjugal e reprodutivo, aquele que se faz na rede ou no roçado. O sexo de Paketawã e sua amante é um sexo provocativo e aventureiro: com a saia curta e as pernas abertas, ela o provoca, e nada nua no rio enquanto ele a observa.

Porém, as aventuras sexuais de Paketawã não param aí. Assim que chega à terra do povo dos Inka, oferece favores sexuais às mulheres inka. Nessa altura o narrador imita, por meio de onomatopéias, o som dos enormes testículos do herói ao bater no chão durante o ato sexual. $\mathrm{O}$ tamanho dos órgãos sexuais assinala o grande investimento do herói nessa área de conhecimento corporal, a parte que será também, ao final do mito, seu tendão de Aquiles.

Nawa Paketawã demonstra um comportamento que, do início ao fim do mito, é declarado insustentável: casa-se demasiadamente próximo, cometendo uma versão suave do incesto, e rouba a mulher do cunhado; envolve-se com o que é demasiadamente diferente, com o povo dos Inka, emblema da alteridade. $\mathrm{O}$ resultado é que aquele que um dia foi irmão transforma-se em estrangeiro para Nete. E, quando ela resolve visitá-lo, terá de encarar o inimigo na figura de quem considera um parente reencontrado. Descobrirá tarde demais que Paketawã se tornou, por meio do intercurso, da partilha e da coexistência pacífica com o Inka, ele mesmo, um Inka. Para ver o que sucedeu ao irmão, Nete empreende uma longa viagem rio acima, segue os rios de cores diferentes que o irmão seguiu e chega finalmente a um barranco onde ele construiu sua casa, perto da casa do Inka.

Por meio de descrições detalhadas das transgressões do amor apresentadas nesse mito, aprendemos muito sobre a etiqueta moral dos Kaxinawa, assim como sobre as situações específicas relacionadas a tipos 
de associações amorosas particulares. As aventuras licensiosas de figuras como Paketawã e Bane podem ser contraprodutivas em termos de trocas sociais normativas, mas apresentam eficácia e produtividade no domínio da pesca, alimento muito apreciado.

Ou seja, o que produz problemas internos (na relação pessoas-corpos) pode significar sucesso no relacionamento produtivo com o mundo aquático, que gosta do cheiro de sexo. Mitos e fofocas indicam que existe entre os Kaxinawa uma certa tolerância com relação a aventuras extraconjugais. Só que estas não podem se tornar públicas nem fonte de sofrimento para o parceiro, senão leva a migrações e separações do tipo que acabamos de conhecer. A figura do marido excessivamente ciumento, como a onça-pintada, também provoca risos, pois remete ao risco da paralisação, em que o marido possessivo e inseguro não consegue mais caçar porque só pensa em controlar a mulher.

$\mathrm{O}$ riso do mito e das narrativas, portanto, trabalha as nuances do delicado equilíbrio relacional que diz respeito ao comércio carnal e às relaçôes afetivas. O humor entra, desse modo, no registro do conhecimento relacional, a base de todo conhecimento de agir sobre e construir o mundo, e garante a possibilidade de tratar de assuntos delicados sem ofender ou produzir face-loss. Nesse sentido, surge a importância da linguagem icônica, que presentifica modalidades possíveis do ser sem entrar no registro denotativo e acusatório. $\mathrm{O}$ riso cria um espaço para a imaginação social, na qual cada um pode decidir por conta própria os termos das relaçóes e possibilidades de ação e reação invocadas nos mitos, nas performances e nas narrativas. Assim vemos que não são apenas os amantes ousados ou os maridos ciumentos os alvos do riso coletivo; figura mais engraçada ainda é o homem que recusa qualquer interação social. 


\section{Neabu e o caminho da miçanga}

Este mito trata dos quereres conflitantes de um casal, o dele por dentes e o dela por contas. O casal anda na floresta e na encruzilhada, o homem escolhe o caminho na direção das nascentes do rio, e a mulher toma o rumo da jusante. Ela é muito bonita. O casal discute: "Vamos na direção dos dentes", insiste o marido. A mulher responde: "Não! Vamos na direção das miçangas". Assim foi, cada um chamando o outro, cada um tentando convencer o parceiro a mudar de idéia. Mas de nada adiantou. Quando Neabu percebe que não escuta mais a voz da mulher, em desespero sobe na árvore mais alta que encontra e a chama, porém, não obtém resposta. A mulher está longe e não o escuta mais. Perturbado, ele cai da árvore e, quando consegue ficar de pé, comporta-se como "louco", repetindo a mesma frase todo o tempo: "minha mulher, minha mulher, minha mulher!..." (essa frase foi motivo de muito riso).

Neabu continua sua viagem à procura de seus tios, os basabu keneya, um grupo de Yaminawa que vive nas cabeceiras dos rios. No caminho, encontra duas mulheres que estão viajando para encontrar os Inka. Quando vêem Neabu, chamam-no para comer com elas, mas ele não diz uma palavra: senta no chão, encolhe a cabeça entre os ombros e se encosta contra uma árvore. No momento em que as irmãs vão dormir, convidam-no para dormir com elas em sua rede, mas Neabu permanece no mesmo lugar. Enquanto as mulheres dormem, ele mastiga os ossos que as irmãs jogaram fora, enrosca seu corpo e dorme no chão. Quando as viajantes juntam seus pertences e retomam a viagem, Neabu as segue, escondendo-se atrás das árvores. E, no momento em que elas finalmente encontram os maridos inka, Neabu grita "são minhas mulheres, minhas mulheres!” (todos riem muito, inclusive o próprio narrador). 
A separação transforma Neabu em uma criatura boba e mal ajustada, enquanto sua mulher, que está a caminho de se transformar em estrangeira, não foi mais vista, nunca mais voltou. Seu desejo obstinado por contas era tão forte que a fez viajar sozinha, abandonando o marido. Esse trecho recebeu a interpretação de Augusto, velho contador e líder de canto, que se refere a esse episódio do ponto de vista das relaçóes de parentesco: o pai da mulher estaria entre aqueles que conseguiram atravessar a ponte do jacaré (e assim se tornaram brancos, donos das miçangas), e o motivo real para a fascinação dela por miçanga seria o desejo de rever os parentes. Assim, a motivação para as pessoas se movimentarem parece ser a vontade de se reunir com os parentes mais próximos. Porém, em outra ocasião, a explicação de Augusto foi outra:

"Você vê? [Augusto disse com sorriso irônico.] Isso explica por que as mulheres gostam tanto de miçanga, por que todas querem que você traga muita miçanga - elas ficam alegres (benimai). Elas querem ser bonitas, tão bonitas quanto os Shipibo, que têm colares grandes e pesados, cruzados no peito, assim, cheios de miçanga. Nós, homens, queremos que você nos traga muita munição para caçar e fazer colares de dentes de macaco".

Os bens dos Inka e dos nawa, brancos, precisam ser conquistados ou pagos ao preço de se tornar, como a esposa de Neabu, um estrangeiro. Não obstante, os bens desejados do estrangeiro constituem, ao mesmo tempo, a estrutura mais interior da vida social e do corpo. Essa consciência da presença constitutiva da alteridade, no que é considerado o mais interior, é uma temática recorrente na mitologia e nos cantos rituais. Nesses cantos, os ossos são feitos de Inkan mane (contas, metal do Inka) e de xeki bedu (olhos, sementes de milho), alimento do Inka. O milho vem do Inka, o sêmen da caiçuma de milho, e do sêmen são 
feitos os ossos da criança. O fogo também foi roubado do Inka, e do fogo nasceu a humanidade.

Inka, alteridade suprema, é igualmente o Inka kuin, o destino do espírito do olho da pessoa, seu devir pessoa, um tornar-se mesmo tanto quanto outro por meio da morte. Na escatologia kaxinawa, a aldeia dos Inka é descrita como uma aldeia no estilo dos antigos (xenipabu). Os Inka são descritos como a apoteose do ser kaxinawa: totalmente adornados, acumulando todos os tipos de dau (ornamentos, remédios) que uma pessoa possa adquirir durante a vida. O Inka se apresenta para receber a recém-chegada todo ornamentado. Como marido da mulher falecida, ele recebe sua nova esposa tocando flauta, instrumento usado somente no contexto da sedução sexual. O Inka da morte, portanto, é huni kuin, o mais próprio "eu" da identidade kaxinawa.

Nos mitos são narradas as causas da separação e da diferença entre os tipos de homens. O Inka e o nawa são proprietários de bens que pertencem à civilização urbana. No mito possuem o fogo e as plantas cultivadas, na história do contato, o metal, as espingardas, os facões e as máquinas. Seu comportamento é caracterizado pela crueldade, falta de reciprocidade e avareza. Mas esse não é seu caráter intrínseco, trata-se de uma qualidade relacional associada com o excesso de alteridade, porque tanto os Inka quanto os nawa, brancos, podem ser transformados em "seres humanos como nós" (a autodenominação, huni kuin) por meio de um tipo de domesticação aplicado também a animais selvagens. Seu corpo-mente é acostumado ao novo ambiente, e esse processo se chama yudawa, fazer o corpo. Esse processo é realizado por meio da partilha de memórias e substâncias e, com base nelas, começam a se assemelhar cada vez mais, como acontece com marido e mulher, que depois de um tempo de convivência acabam se parecendo. 
Desse mesmo tema tratam as brincadeiras damiwa, que fazem rir dos outros poderosos, estrangeiros que podem, no entanto, ser desarmados por meio do riso e tornar-se como parentes. A ambigüidade do conceito inka, simultaneamente o mais "eu" (kuin) e o mais "outro" (nawa) dos seres, é uma mensagem sobre a potencialidade da igualdade na diferença e na oposição. Em outros contextos, volta a mesma idéia. Jovem e velho, a cor branca e preta, masculino e feminino, todos são vistos como pares entrelaçados pela interdependência, pontos de vista e posiçóes possíveis de serem ocupados por qualquer ser vivo em algum momento de sua existência. Um tipo específico do "brincar com inversões" (transformar, imitar ou fazer de conta) é o damiain, traduzido como brincadeira, brincar de branco.

\section{Damiain, brincar de branco}

Dami é um conceito-chave no quadro de referência que organiza a percepção kaxinawa do mundo. É o elo que liga fenômenos distintos, pois fala da relação entre o objeto e sua imagem, que pode ser de transformação, representação aproximada, evocação ou presentificação. Dami é, antes de mais nada, um conceito processual, que indica um devir ou um "fazer" de conta. É esta última acepção que nos interessa aqui (ver Lagrou, 1998). No caso do damiain, trata-se de um exercício do "tornar-se outro" para melhor "se tornar o mesmo", traduzido como "brincar de branco". Trata-se de sketches, pequenas apresentações cômicas, em que os palhaços se vestem de branco. A cena muito curta que presenciei representava seringueiros bêbados e completamente desajeitados. A hilaridade provocada se devia à combinação de suas intenções agressivas com o comportamento totalmente desajeitado e incompetente do bêbado. 
Revista de Antropologia, São Paulo, USP, 2006, v. 49 no 1.

Uma primeira reflexão sugere que se ri da figura do poder. Os Kaxinawa informaram a McCallum que existia o hábito de representar o povo inka nas festas de máscara designadas damiain. Damiain seria uma caricata teatralização cômica que transforma o "medo do Inka" em riso. $\mathrm{Na}$ palhaçada presenciada por McCallum (2000, p. 384-6) em 1990, no entanto, os Inka tinham sido substituídos por um cariú, um branco que negociava com o líder kaxinawa a venda do que viria a ser o terreno onde seria construída a aldeia. Em 1991, quando vi outro damiain, "seringueiros bêbados" substituíam igualmente os Inka canibais.

Rir com e ridicularizar a figura do poder é um fenômeno bastante conhecido. Trata-se desse riso subversivo de que falam tantas paródias do colonialismo e a que se refere também Bakhtin ao analisar o riso popular. Quando aplicamos ao seringueiro a lógica relacional que detectamos acima para o Inka, no entanto, essa interpretação ganha outro caráter. Mostra que o outro representa sempre uma possibilidade latente do ser, presente em nós mesmos, e se associa a uma teoria relacional da identidade, em que o outro pode se tornar igual a nós mesmos e o mesmo pode se tornar outro. $\mathrm{O}$ bêbado que se torna violento e ao mesmo tempo desajeitado, a ponto de cair desmaiado no chão onde permanecerá por horas, por exemplo, é uma cena nenhum pouco estranha à experiência kaxinawa. É um cenário associado à convivência com o branco, mas que de maneira alguma caracteriza um comportamento exclusivo dos seringueiros. Os Kaxinawa e outros indígenas gostam de experimentar esse estado alterado. A bebida forte é um dos produtos que os brancos têm para trocar ou vender e que alguns homens indígenas desejam em contextos bem específicos.

Os rituais tradicionais, regados a caiçuma fermentada, são muito recorrentes na região e visam o efeito similar de todos se embebedarem enquanto dançam e celebram. Essas bebidas, no entanto, são muito menos concentradas que a cachaça e têm efeito e uso que mais se asse- 
melham ao uso social e festivo da cerveja. O uso isolado da cachaça se parece mais com o uso ritualmente controlado de tipos específicos de alucinógenos, como o caso descrito por Gonçalves (1997) para os Pirahã. Estes costumavam cheirar o pó de pariká, que os transformava em outros, deixando-os valentes como brancos ou como onças. Somente um homem cheirava a cada vez, enquanto os outros o seguravam, impedindo-o de causar mal aos seus, pois, no estado em que se encontrava, não os reconhecia mais como tal. Hoje em dia os Pirahã usam cachaça em vez de pariká.

Os Kaxinawa conhecem vários contextos rituais nos quais se experimenta, por via mimética, a possibilidade de se tornar temporariamente outro. Os damiain são somente uma de suas versões e são menos esporádicos do que poderia parecer à primeira vista. Assim, no filme chamado Nawa Huni, produzido por Deshayes e Keifenheim (1986), os Kaxinawa do Peru discutem imagens presenciadas em vídeo sobre a vida dos brancos. As imagens suscitaram muitos comentários, inclusive os seguintes: ${ }^{5}$

"Nós também festejamos as festas dos brancos. Nossos antepassados já o faziam. Brincamos suas festas para imitar os brancos. Assim, ensinamos a nossos filhos como são os outros. Fazemos como se fôssemos brancos. Nós os imitamos, gesticulando como eles. Dançamos com facas e espingardas para imitar sua polícia e para imitar seus soldados. Apertamos nossas mulheres na dança como o fazem os brancos. Tudo isso não são nossos costumes. Nós somente os imitamos em frente a nossas crianças." (Weber, 1998)

E Weber continua descrevendo o que vê no filme: "Então eles passam a dançar ao som de uma espécie de cúmbia (ritmo popular do Peru, equivalente ao forró-brega brasileiro), caricaturalmente, com roupas feitas de trapos, espadas na cintura e máscaras de cabaça”. 
Revista de Antropologia, São Paulo, USP, 2006, v. 49 no 1.

Hoje em dia a dança em estilo de forró foi incorporada ao ritmo festivo da aldeia. Nas festas que presenciei nos anos 90, mais do que de uma palhaçada burlesca, como a dos Kaxinawa peruanos dos anos 60 com suas máscaras e seus trapos, tratava-se de um negócio sério. $\mathrm{O}$ ato de apertar uma mulher contra si em público é próprio da dança de forró do branco e era ainda vivido como uma transgressão da etiqueta indígena. Daí o frisson e o clima sério, mas não era mais assunto de piada. Com o esquentar da festa, as pessoas relaxavam mais, mas não percebi a mesma descontração e o divertimento que marcam as fases carnavalescas dos ritos, como o rito de passagem e o ritual de fertilidade. Uma das razões da tensão do forró é a possibilidade latente de briga, porque, especialmente quando embriagados, os homens podem ficar com ciúme de suas mulheres.

As situações nas quais os Kaxinawa "brincam de branco" são múltiplas. Assim, por exemplo, colecionavam durante o período de inflação notas que tinham saído de circulação para brincar de compra e venda na própria aldeia. Quando as mulheres voltavam de uma colheita na floresta, trazendo algum tipo de coquinho ou fruto, os homens na aldeia se apressavam para inventar um tipo de feirinha, onde adultos e crianças pudessem comprar os frutos. Nesse tipo de brincadeira, somente se comercializavam produtos extras, como são consideradas as frutas coletadas na floresta. Em 1998 Weber observou, numa visita à escola indígena, uma versão muito mais elaborada desse tipo de brincadeira, chamada de "brincadeira do dinheiro-papel".

'O 'dinheiro-papel' são notas de papel rodadas no mimeógrafo, todas com o 'título' 'Banco Central do Índio', sendo que cada valor é ilustrado com um animal diferente. $\mathrm{O}$ presidente do banco e da aldeia é o próprio Manuel Sampaio, mas, além dessa autoridade máxima, existem outras que foram eleitas pela comunidade quando foram montadas três chapas, do 
PFL, do PT e um terceiro partido, cada qual contendo um prefeito, o vice, o deputado, o senador e o vereador... Todas essas autoridades recebem um salário no dinheiro do Banco Central do Índio, tornando-se, assim, os principais 'detentores de capital' da aldeia. Para receber o salário, é preciso que cada um tenha o seu RG e CPF, que também são emitidos lá mesmo.” (Weber, 1998)

Num primeiro momento, as professoras da CPI, enviadas para controlar a situação da escola, ficaram equivocadas e assustadas com tamanha precisão de mimese. Não poderiam, no entanto, ter tido melhor recepção e melhor demonstração de que os caminhos de apropriação e transformação da alteridade são múltiplos. Como já dizia Benjamin - e Taussig (1993, p. 19) com ele -, "The capacity to mime, and mime well, in other words, is the capacity to Other". Este "alterar" é o caminho para se tornar um "eu" e não um "outro", e essa lição os Pano sempre souberam muito bem. Trata-se da atividade de experimentar o ponto de vista do outro e de incorporar este outro dentro da pessoa, sem aniquilá-lo nem deixar de ser o que se é. Os Kaxinawa estão decididamente convictos de que é brincando que se aprende. Tanto o riso provocado pelo caráter grotesco do outro imitado quanto a mimese imagética que se apropria da imagem do outro - às vezes, como na experiência visionária, entrando nela - são maneiras não de neutralizar o outro poderoso, mas de partilhar e se apropriar de parte de sua agência, aumentando dessa maneira a própria subjetividade do brincante. Esse é o secreto poder do humor: capturar o modo de conhecimento do outro, fazer e dizer o que de outro modo seria indizível, e dessa maneira se apropriar do modo de conhecimento e agência do outro sem se deixar englobar por ele. 


\section{"Nosso carnaval": \\ o grotesco na mímica gestual da "guerra dos sexos"}

O humor tem um papel de destaque na performance de narrativas, como o recontar as vicissitudes e proezas de uma expedição de caça, e na narração de mitos. A performance requer um domínio especial da expressividade gestual e retórica, que explora a sensibilidade do público para o grotesco e para as situaçóes ridículas ou engraçadas experimentadas pelos protagonistas da história. O humor é crucial para uma narração bemsucedida, e a platéia responde com risos e comentários. $\mathrm{O}$ caráter interativo desse tipo de evento é evidente e, apesar dos mitos terem uma trama fixa, nenhuma narração reproduz outra de forma idêntica. Os narradores têm a liberdade de incluir ou excluir detalhes ou partes específicas da história, e a audiência pode solicitar a inclusão de partes omitidas, incitando o narrador a se dedicar às partes mais engraçadas.

O humor está presente também no ritual de fertilidade, katxanawa, na forma de poesias cantadas. Esse é o ritual mais freqüentemente celebrado pelos Kaxinawa, pois sua execução independe da periodicidade relacionada ao calendário agrícola. Tanto os homens quanto as mulheres podem iniciar o ritual. No segundo caso, trata-se de um ritual com inversão dos papéis de gênero. Um grupo de mulheres de uma metade invade a aldeia, cada mulher coberta por folhas de jarina para esconder sua identidade. O grupo é recebido pelo grupo de mulheres da metade oposta, que correm a seu encontro armadas com espingardas, que são disparadas. As “invasoras” são cercadas pelo grupo de anfitriãs e guiadas para o terreiro, onde dançam em círculo durante um período curto, quando tiram a roupa de folha de jarina para revelar sua identidade e as intenções pacíficas. Os homens permanecem sérios e observam, enquanto as mulheres se divertem. 
Os homens, por sua vez, divertem-se ao vestirem as roupas de suas mulheres, usando saias e colares, carregando as crianças. "Este é nosso carnaval", explica a liderança da aldeia. No katxanawa feminino, serão também as mulheres que começam a dança ao redor da paxiúba oca. Os homens logo se juntam e, com cantos improvisados, a provocação mútua começa. Esses cantos rituais são chamados de xebi itxa (insultar a vagina) e hina itxa (insultar o pênis), isto é, o xingamento (ou elogio?) mútuo das vaginas e dos pênis. Como exemplo do canto que "insulta" a vagina, cito este improvisado pela jovem liderança da aldeia em 1995:

Hem, hem, vagina, vagina, a vagina é peluda, hem, hem (Hem hem hita hita tapa tapadania hem hem) [duas vezes]. É lisa, é lisa, é muito lisa (ha bixtun ha bixtun ha bixtun ha bixtun). Hem, hem, vagina, vagina, a vagina é peluda, hem, hem. É lisa, é lisa, é muito lisa, sua beira é lisa, sua beira é lisa (kebixtun kebixtun kebixtun kebixtun). É lisa, é lisa, é muito lisa. Hem, hem, vagina, vagina, a vagina é peluda, hem, hem. Passa o liso para o ânus. Passa o liso para o ânus, passa o liso para o ânus (txibixtun) [seis vezes]. Hem, hem, vagina, vagina, a vagina é peluda, hem, hem.

Esses poemas eróticos são exemplos de competição poética, em que as metáforas ou descrições provocativas e insultantes mais inventivas são recebidas com gritos de aprovação e indignação. Mulheres e homens agem em blocos antagônicos, enfrentando a coletividade oposta. Apesar de um dos gêneros iniciar a dança, ela só se torna animada quando o outro grupo se junta ao primeiro e começa a cantar-gritar seus "insultos elogiosos" enquanto resposta coletiva. As ofensas, como "morcego-vampiro" (para se referir à vagina) ou "pescoço de tartaruga" (para se referir ao pênis), nunca são dirigidas a alvos individuais, mas celebram de forma coletiva os aspectos antagônicos da atração dos sexos (McCallum, 1989). Nessa performance a improvisação é valorizada, produzindo ani- 
Revista de Antropologia, São Paulo, USP, 2006, v. 49 no 1.

mação e participação coletiva. Essa performance parece deixar os participantes muito mais à vontade para provocar e manifestar toda sua ousadia do que a dança de casal no forró, em que se dança a dois, sem trocar uma palavra, sendo cada movimento atentamente observado pelos outros.

O rito de passagem, nixpupima, contém igualmente episódios humorísticos de antagonismo de gênero ritualizado. Puinkimei é uma provocação masculina dirigida às mulheres que consiste em mostrar o traseiro - um gesto recorrente durante todo o ritual. A ousadia dos homens na imitação grotesca da fertilidade feminina vai crescendo com o possível clímax na pintura vermelha das nádegas - presenciada por Kensinger (notas de campo) no Peru. O máximo que presenciei foi o baixar de calças, recebido com muita hilaridade entre as mulheres. Segundo Kensinger, os homens afirmam que o vermelho do urucum representa o sangue do parto, enquanto as mulheres retrucam que representa o sangue menstrual.

Outro exemplo de demonstração humorística de antagonismo ocorre durante a fase final do nixpupima, desta vez com relação à atração dos opostos. Trata-se de uma pantomima que representa o ato sexual dos pontos de vista, respectivamente, feminino e masculino. Essa parte do ritual é vedada aos olhos das crianças. Homens e mulheres jovens formam fileiras nos lados opostos do rio. As mulheres seguram espigas de milho, uma em cada mão, com as folhas viradas para baixo. Ao cantar o canto taku taku, abanam a espiga para cima e para baixo. Do outro lado do terreiro, os homens estão armados com arco e flecha em miniatura. As mulheres começam o ataque, avançam sobre seus cunhados, cutucando-os com as espigas. Os homens fogem, tentando obter a distância necessária para atirar nas saias das atacantes. A "briga" acaba envolvendo a maior parte dos homens e das mulheres da aldeia, que se divertem, gritam e riem. As mulheres se unem em grupos de três para melhor 
enfrentar os homens. Quando cansadas, debulham a espiga, jogando os grãos no chão. Esse ato provoca muita hilaridade, pois é uma imitação da ejaculação. Novamente, os homens respondem com flechadas na direção do sexo oposto.

Outra cena de "enfrentamento" ocorre sempre no final de uma sessão de cantos rituais para "alegrar" os donos das substâncias e os seres chamados a participar do ritual do nixpupma. Homens e mulheres imitam diferentes tipos de animais que se enfrentam, gritando e pulando. $\mathrm{O}$ final apoteótico do ritual é novamente vedado aos olhos das crianças, que, no entanto, podem ouvir os gritos e risos dos adultos divertindo-se com a brincadeira da lama. Homens e mulheres jogam lama uns nos outros, eles abaixam as calças para mostrar as nádegas, e a brincadeira só termina quando todo mundo está absolutamente lambuzado. Finalmente, cansados e cobertos de barro, homens e mulheres se retiram para se banhar.

Os Kaxinawa dão grande importância à influência do ânimo na eficácia ritual. Somente quando o canto é bem cantado, em voz alta e forte, com vontade e alegria, é que o dono da substância estará presente na aplicação do seu produto, deixando a substância permeada pela agência, vitalidade e intencionalidade do seu dono. Precisa-se do poder dos cantos para intimar os donos invisíveis das espécies, para torná-los presentes e alegrá-los, para fazê-los escutar e entender, para que se possa obter um ritual eficaz, bem-sucedido, em que o aspecto semântico da linguagem poética é inseparável de sua força ilocucional.

A mesma lógica se aplica à eficácia ritual do grotesco, do lado carnavalesco do ritual com sua mimese, paródia e jocosidade. Todas essas brincadeiras, tão recorrentes nos rituais kaxinawa, servem para criar a famosa "moral alta", segredo das sociedades afluentes amazônicas (Overing, 1988, 1989, 1992; Goldman, 1963; Clastres, 2003). As lideranças, sem poder de coerção, só conseguem fazer com que as pessoas se engagem em trabalhos coletivos, como a derrubada dos roçados, crian- 
Revista de Antropologia, São Paulo, USP, 2006, v. 49 no 1.

do um clima festivo que anime as pessoas a se juntarem por livre e espontânea vontade à empreitada coletiva.

Os Kaxinawa estendem essa lógica a sua negociação com o mundo não humano que os envolve, habitado por seres com intencionalidades próprias, que precisam ser "alegrados" (benimai) para colaborarem na afluência e fertilidade geral, de humanos, animais e plantas. Os cantos iniciais do ritual são chamados de cantos para "alegrar as estrelas" (bixi benimai) e todos os donos da floresta, da água e do céu. As atitudes dos Kaxinawa perante a eficácia dos cantos leva a teoria do ato de fala de Austin a sério: palavras não somente nos informam sobre o mundo, mas agem sobre o mundo de forma poderosa (Tambiah, 1979, p. 119; Austin, 1989). Assim um dos cantos do katxanawa é chamado bake kenaki, "chamar criança", e afirma que o alimento vegetal é transformado em sêmen. A canção inicia com o milho e prossegue com a invocação das caiçumas feitas de todos os tipos possíveis de vegetais (banana, macaxeira, mamão, batata, cana-de-açúcar, urucum, algodão, pimenta, palmito e tabaco). A caiçuma é feita de mandioca, banana doce ou milho e, como opção, pode ser misturada ao amendoim torrado e moído. A invocação das caiçumas, associadas às plantas não comestíveis, procura ligar explicitamente a fertilidade humana e vegetal. Cada invocação de uma planta é seguida pela frase "pondo na barriga dela". Vejamos uma parte da transcrição da canção:

Ho, ho, ho, ho [três vezes], pondo na barriga dela. Ho, ho, ho, ho, Banu [nome para mulher da metade inu] está fazendo caiçuma para inu [nome para homens da metade inu]. Ho, ho, ho, ho. Estamos enchendo o interior dela [com nosso sêmen]. Ho, ho, ho, ho, caiçuma de milho, ho, ho, ho, ho. Enchendo-a, já está se tornando uma criança. Ho, ho, ho, ho. Copulando, colocando para dentro. Ho, ho, ho, ho, caiçuma de amendoim. Ho, ho, ho, ho, pondo na barriga dela. (Milton Maia Kaxinawa) 
Espera-se que as mulheres que escutam esse canto engravidem logo. A canção é entoada por jovens e homens maduros que dançam em círculos em volta do tronco oco da árvore. $\mathrm{O}$ ritmo da dança gradualmente aumenta, e o canto se torna cada vez mais alto à medida que as pessoas ficam mais estimuladas (usualmente com a ajuda da cachaça). A canção faz uma ligação explícita entre a produção de sêmen e a bebida de caiçuma de milho, oferecida pelas esposas potenciais aos maridos potenciais, e opera desse modo no registro do humor: ri-se porque o canto explicita o que ninguém diria em condições sóbrias.

Para demonstrar a importância dada ao poder invocativo desse canto, o contexto de sua gravação é revelador. Sendo impossível sua transcrição por causa dos gritos e da hilaridade generalizada durante o ritual, pedi a Milton Maia para cantá-lo novamente para mim. Ele concordou, redefinindo todo o setting da performance: "Tudo bem, vou cantá-lo de novo. Você quer escutar o 'chamar bebê'. Não sei bem como cantá-lo, sabe. Vou cantá-lo para você como de mentira”. Depois dessa advertência, cantou a canção em voz baixíssima, para não atrair nenhuma intencionalidade desavisada que quisesse ajudar na concretização do pedido expresso pelo canto.

Somente durante os rituais que visam aumentar a fertilidade, a provocação por meio de insultos sexuais (convites disfarçados) e brigas de brincadeira entre os sexos de metades opostas tornam-se regra. A comunidade inteira comporta-se como um jovem casal, jocosa e abertamente "despertando" o desejo sexual e invocando os poderes yuxin da fertilidade. "Quando nós pedimos a fertilidade das plantas e a abundância em nossas roças", explica Milton Maia, "estamos ao mesmo tempo pedindo a fertilidade da nossa gente. Uma aldeia feliz é uma aldeia onde muitos bebês nascem." 
No entanto, o humor burlesco, que tanto marca os rituais de fertilidade, não é ausente do cotidiano. Onipresente nas brincadeiras entre cunhados, ele reaparece na relação entre os gêneros na figura do jovem casal. Um jovem casal será visto muitas vezes brincando e se provocando mutuamente em público. Regularmente desaparecem juntos por entre as roças ou a floresta sem necessitar de desculpas ou alguma razão especial senão aquela de "trabalhar" na criança. As pessoas fazem piada mais para dar apoio do que para controlar o casal "sem-vergonha". Sua situação difere da dos outros casais, mais jovens ou mais velhos, que são tão discretos que nunca são vistos se tocando em público. Os primeiros porque sua liaison é secreta, e os últimos porque eles e os outros estão tão habituados com sua relação que qualquer ostentação tornar-se-ia inapropriada. Manifestar publicamente afeição é agora reservado à sua relação com os filhos pequenos.

\section{Conclusão}

Minha intenção foi mostrar como o humor grotesco das pantomimas e dos mitos, o humor festivo das brincadeiras e o humor crítico dos excessos em narrativas, mitos e brincadeiras do damiain podem ser lidos como formas de conhecimento nativo sobre o mundo. A exegese nativa da imagética humorística usada em narrativas, cantos e pantomimas nos revela valores cruciais relacionados às concepçôes kaxinawa sobre socialidade, convivialidade e pessoalidade. Estamos lidando com discursos icônicos sobre a qualidade das relações entre pessoas e entre as pessoas e o mundo - que é habitado por seres com intencionalidades próprias. Estes últimos precisam ser alegrados, cooptados e seduzidos para colaborar. Tanto o humor do corpo grotesco, que faz dialogarem 
partes de corpos como forças autônomas (como no exemplo da briga entre espigas de milho e flechas em miniatura), quanto o humor meramente festivo, cujo riso contamina a moral dos "donos" das substâncias, têm alta eficácia ritual. Motivam as forças cósmicas a agirem em prol da humanidade.

Qual é o saber expresso pelo humor? O humor festivo e burlesco do ritual expressa um conhecimento de como agir sobre o mundo que os protagonistas dos mitos careciam. Nos mitos, os poderosos donos de saberes cruciais à vida eram conquistados e mortos, como Inka ou Paketawã. No ritual estes mesmos seres são "alegrados" e seduzidos, fazem-se gracejos e pantomimas grotescas, tudo para invocar a força de seu riso poderoso e criador. $\mathrm{O}$ uso de imagens produtivas e alegres no canto ritual subverte o tempo mítico do conflito para produzir o tempo histórico, um tempo no qual corpos e pessoas são produzidos com base nas qualidades construtivas de seres poderosos, conhecidos por suas capacidades predatórias. O ritual seduz inimigos a colaborarem por meio da eficácia poética de belas imagens e da eficácia desarmadora do riso festivo que alegra, criando a alta moral da festa, marcada pelo exagero, pelo grotesco e pelo burlesco.

\section{Notas}

1 Gonçalves (2002) e Belaunde (2001, p. 60-2) dão ilustrações eloqüentes de deuses imperfeitos e risíveis entre os Pirahã e do deus trickster entre os Airo-Pai, respectivamente.

2 Fiz pesquisa de campo entre os Kaxinawa (de língua pano) da área indígena do Alto Purus no estado do Acre (região fronteiriça com o Peru) durante um período de 18 meses (entre 1989 e 1995). A população total dos Kaxinawa gira em torno de 7 mil pessoas no Acre. 
Revista de Antropologia, São Paulo, USP, 2006, v. 49 no 1.

3 Várias etnografias mencionam a importância do humor em rituais indígenas: Erikson (1996); Carid (1999); McCallum (1989) e Kensinger (1995) para os Pano; Mello (2005) e Basso (1987) para o Xingu.

4 CPI-Acre (1996); D’Ans (1975); Agostinho Manduca coletada por mim.

5 Os comentários foram transcritos e gentilmente cedidos por Ingrid Weber (1998).

\section{Bibliografia}

ALBERTI, Verena

2002 O riso e o risivel na história do pensamento, Rio de Janeiro, Jorge Zahar.

AUSTIN, John L.

1962

How to Do Things with Words, Cambridge, MA, Harvard University Press.

BAKHTIN, Mikhail

1993

A cultura popular na Idade Média e no Renascimento. O contexto de François Rabelais, São Paulo/Brasília, Hucitec/Editora da UnB.

BASSO, Ellen

In Favor of Deceit: A Study of Tricksters in an Amazonian Society, Tucson, The University of Arizona Press.

BATESON, George

1972 Steps to an Ecology of Mind, New York, Ballantine Books.

BEAUDET, Jean-Michel

1996 “Rire. Um exemple d'Amazonie”, L'Homme,140: 81-99.

BELAUNDE, Elvira

2001 Viviendo bien. Gênero y fertilidad entre los Airo-Pai de la amazonía peruana, Lima, CAAAP.

CARID, M. Naveira

1999

Yawanawa: da guerra à festa, dissertação de mestrado, Florianópolis, UFSC. 
Lagrou, E. Rir Do PODER E O PODER DO Riso NAS NARRATIVAS...

CARNEIRO DA CUNHA, Manuela

1978 Os mortos e os Outros: uma análise do sistema funerário e da noção de pessoa entre os indios Krahó, São Paulo, Hucitec.

CLASTRES, Pierre

2003 A sociedade contra o Estado. Pesquisas de antropologia política, São Paulo, Cosac \& Naify.

CPI-ACRE

1996

Shenipabu Miyui. História dos antigos, Rio Branco, Comissão Pró-Índio do Acre.

D’ANS, André Marcel

1975 La verdadera biblia de los Cashinahua, Lima, Mosca Azul.

DESHAYES, Patrick \& KEIFENHEIM, Barbara

$1986 \quad$ Nawa Huni: regard indien sur l'autre monde. (60 min.)

DOUGLAS, Mary

1966 Purity and Danger: An Analysis of the Concepts of Pollution and Taboo, London/ New York, Arks Paperbacks.

ERIKSON, Philippe

1996 La griffe des Aïeux. Marquage du corps et démarquages ethniques chez les Matis d'Amazonie, Louvain/Paris, Peeters.

GADAMER, Hans-Georg

1995 The Relevance of the Beautiful and Other Essays, Cambridge, Cambridge University Press.

GELL, Alfred

"The Technology of Enchantment and the Enchantment of Technology", in COOTE \& SHELTON (ed.), Anthropology, Art and Aesthetics, Oxford, Clarendon Press, pp. 40-63.

GOLDMAN, Irving 1963

The Cubeo. Indians of the Northwest Amazon, Urbana, The University of Illinois Press. 
GONÇALVES, Marco Antonio

1997

"Paricá and Cachaça: Alterity and Predation in Pirahã Cosmology", Amerindian Seminars, St. Andrews University, ms.

2001

O mundo inacabado: ação e criação em uma cosmologia amazônica. Os Pirahã, Rio de Janeiro, Editora da UFRJ.

HUIZINGA, Johan

1980 Homo Ludens, São Paulo, Perspectiva.

KENSINGER, Kenneth

1995 How Real People Ought To Live: The Cashinahua of Eastern Peru, Prospect Heights, IL, Waveland Press.

LAGROU, Els

1998

Duplos, corpos e caminhos: uma abordagem perspectivista da identidade e alteridade kaxinawa, Ph.D. dissertation, University of St. Andrews/doutorado, USP.

2000 "Homesickness and the Cashinahua Self: A Reflection on the Embodied Condition of Relatedness", in OVERING, Joanna \& PASSES, Alan (ed.), The Anthropology of Love and Anger. The Aesthetics of Conviviality in Native Amazonia, London/New York, Routledge, pp. 152-69.

2001

"Alteridade e identidade de uma perspectiva kaxinawa", in ESTRECI, N., FRY, P. \& GOLDENBERG, M. (ed.), Fazendo antropologia no Brasil, Rio de Janeiro, Capes/DP\&A, pp. 93-127.

LEACH, Edmund

1972

"Anthropological Aspects of Language: Animal Categories and Verbal Abuse", in LESSA, William A. \& VOGT, Evon Z. (ed.), Reader in Comparative Religion, New York, Harper \& Row, pp. 206-20.

LÉVI-STRAUSS, Claude

1991 O cru e o cozido. Mitológicas, São Paulo, Brasiliense.

MAUSS, Marcel

1969 "Parentés à plaisanteries", in Oeuvres, Paris, Minuit, pp. 109-25. 
LAGRou, E. RiR Do PODER E O PODER DO RISO NAS NARRATIVAS...

\section{MCCALLUM, Cecilia}

1989

2000

"Vampire Bats and Tortoise Necks. A Reanalysis of Rituals of Sexual Antagonism in Amazonia", ms.

Kaxinawa”, in ALBERT, Bruce \& RAMOS, Alcida Rita (ed.), Pacificando o branco. Cosmologia do contato no norte amazônico, São Paulo, Editora da UNESP, pp. $375-401$.

2001 Gender and Sociality in Amazônia. How Real People are Made, Oxford/New York, Berg.

MELLO, Maria Inês Cruz

2005 Iamarikumã: música, mito e ritual entre os Wauja do Alto Xingu, dissertação de mestrado, Florianópolis, UFCS.

NIETZCHE, Friedrich

1966 Beyond Good and Evil, New York, Random House.

OVERING, Joanna

1985

"There Is No End of Evil: The Guilty Inno-cents and their Fallible God", in PARKIN, David (ed.), The Anthropology of Evil, London, Blackwell, pp. 24478.

1986

"Men Control Women? The Catch-22 in the Analysis of Gender", International Journal of Moral and Social Studies, vol. 1(2): 135-56.

1988 "Personal Autonomy and the Domestication of Self in Piaroa Society", in JAHODA, Gustav \& LEWIS, Ioan M. (ed.), Acquiring Cultures: Cross-Cultural Studies in Child Development, London, Croom Helm, pp. 169-92.

1989 "The Aesthetics of Production: The Sense of Community among the Cubeo and Piaroa", Dialectical Anthropology, vol. 14: 159-75.

1993 "The Anarchy and Collectivism of the 'Primitive Other': Marx and Sahlins in the Amazon", in HANN, Cristopher M. (ed.), Socialism: Ideals, Ideologies and Local Practices, ASA Monograghs 31, London/New York, Routledge, pp. 4358.

2000 "The Efficacy of Laughter. The Ludic Side of Magic Within Amazonian Sociality", in OVERING, Joanna \& PASSES, Alan (ed.), The Anthropology of Love and Anger. The Aesthetics of Conviviality in Native Amazonia, London/New York, Routledge, pp. 64-81. 
Revista de Antropologia, São Paulo, USP, 2006, v. 49 no 1.

RADCLIFFE-BROWN, Alfred R.

1973 Estrutura e função na sociedade primitiva, Petrópolis, Vozes.

SEEGER, Anthony

1980 Os indios e nós. Estudos sobre sociedades tribais brasileiras, Rio de Janeiro, Campus.

SEEGER, Anthony; DA MATTA, Roberto; VIVEIROS DE CASTRO, Eduardo

1979 "A construção de pessoa nas sociedades indígenas brasileiras", Boletim do Museu Nacional, vol. 32: 2-19.

STEWARD, Susan

1993 On Longing. Narratives of the Miniature, the Gigantic, the Souvenir, the Collection, Durham, Duke University Press.

SURRALLÉS, Alexandre

2003 "¿Por qué el humor hace reír? Humor, amor y modestia ritual en la lírica amazónica”, Amazonia Peruana, vol. 28-9: 87-102.

TAMBIAH, Stanley J.

1979 "A Performative Approach to Ritual", Proceedings of the British Academy, vol. 65: 113-66.

TAUSSIG, Michael

1993 Mimesis and Alterity. A Particular History of the Senses, New York, Routledge.

WEBER, Ingrid

1998 "A brincadeira", relatório de viagem CPI, maio, mimeo. 
ABSTRACT: The grotesque humor of pantomime and myth, the festive humor of play, and the humor used to criticize excesses in myth and comic sketches, can all be read as modes of native knowledge of the world and of the relationships holding this world together. Native exegesis of humoristic imagery reveals crucial values related to Cashinahua concepts about sociality and ritual agency. These are iconic discourses about the quality of relations between people and between people and the animated world. The humor of the grotesque body composed of parts of the body acting as autonomous forces, and the festive humor contaminating the owners of substances, have ritual efficacy, making cosmic powers act in favor of humanity. What kind of knowledge is expressed in humor? Festive and grotesque humor expresses a knowledge of how to act on the world, a knowledge the protagonists of mythic time lacked. In myth, the powerful owners of knowledge crucial to life were conquered and killed. In ritual, these same beings are "made happy" and seduced. Ritual agency thus subverts mythical agency to produce historical time, a time in which bodies are produced out of the constructive qualities of powerful beings known for their predatory capacities.

KEY-WORDS: ethnology, Kaxinawa, festive humor, grotesque humor, ritual, myth. 